\title{
Effect of Concentrator, Blade Diameter and Blade Number on the Savonius Wind Turbine Performance
}

\author{
Ida Bagus Alit ${ }^{1, *}$, Rudy Sutanto ${ }^{2}$, I Made Mara ${ }^{3}$ and Mirmanto Mirmanto ${ }^{4}$ \\ ${ }^{1}$ Mechanical Engineering Department, Engineering Faculty, Mataram University, J1. Majapahit no. 62, Mataram, NTB, 83125, \\ Indonesia \\ ${ }^{2}$ Mechanical Engineering Department, Engineering Faculty, Mataram University, J1. Majapahit no. 62, Mataram, NTB, 83125, \\ Indonesia \\ ${ }^{3}$ Mechanical Engineering Department, Engineering Faculty, Mataram University, J1. Majapahit no. 62, Mataram, NTB, 83125, \\ Indonesia \\ ${ }^{4}$ Mechanical Engineering Department, Engineering Faculty, Mataram University, J1. Majapahit no. 62, Mataram, NTB, 83125, \\ Indonesia \\ * Corresponding author's email: alitbw [AT] yahoo.com
}

\begin{abstract}
Savonius turbine is a type of vertical-axis wind turbines. The turbine has a potential to be developed as it has a simple construction and is suitable for low wind speeds. However, the turbine is still rarely used because of the low efficiency of the turbine compared to other turbines. The low efficiency of the turbine is due to the negative moment. Some efforts have been done to reduce the negative moment such as by adding a wind concentrator. The wind concentrator can steer the incoming wind toward the turbine blades that generate positive moments, consequently, the generated power increases. The aim of this research is to determine the effect of the number and diameter of the Savonius blade wind turbine with an additional concentrator. The concentrator had a concentration ratio of 6:1 and it was tested at the lower wind speeds of 2-5 m/s. The result shows that adding a wind concentrator can increase the rotational speed of the rotor, power coefficient, and the turbine power. The Savonius turbine with two blades has the best performance compared to the three and four blades. The Savonius blade wind turbine with the rotor diameter of $12 \mathrm{~cm}$ is the best Savonius turbine for the concentration ratio of 6:1.
\end{abstract}

Keywords-Savonius wind turbine, concentrators, concentration ratio, power coefficient

\section{INTRODUCTION}

The wind is the environmentally friendly energy and is grouped into renewable energy. Thus it is potential to reduce our dependency on fossil fuel energies. The utilization of wind energy for generating power increases from year to year. A device that can be used to convert wind energy into useful energy is the wind turbine. Based on the direction of the axis orientation [1], the wind turbine can be divided into horizontal and vertical axis wind turbines. Savonius turbine is one type of vertical-axis wind turbines.

Savonius turbine has some advantages such as simple blade shape, enabling to capture any wind direction, allowing the generator placed at the tower bottom, enabling to rotate at quite low wind speeds [2]. The Savonius turbine rotates due to the drag force, which is the difference between positive and negative moments occurring on the blades. The turbine consists of two to three blades and when it is viewed from the above, it forms an S letter [3]. The use of Savonius turbines for generating power is still rare because of its lower efficiency compared to other turbine efficiencies [4].

Some researchers have been improving the performance of the Savonius turbine such as adding the fins on the turbine blades, varying the blades number, installing external overlap [5]. The additional concentrator has also been investigated in order to reduce the negative moment of the rotor and increase the speed of the rotor [6]. Moreover, the effect of concentration ratios has also been studied in order to obtain the optimal design concentrator.

Based on the theory, the size of the power generated from the turbine is strongly influenced by the swept area and wind speed and it can be calculated from the following equation [7]:

$$
P=\frac{1}{2} \rho A_{s} C_{p} V^{3}
$$


Where $P$ is the power, $\rho$ is the wind/air density, $V$ is the wind velocity, $A_{s}$ is the swept area, and $C_{p}$ is the power coefficient.
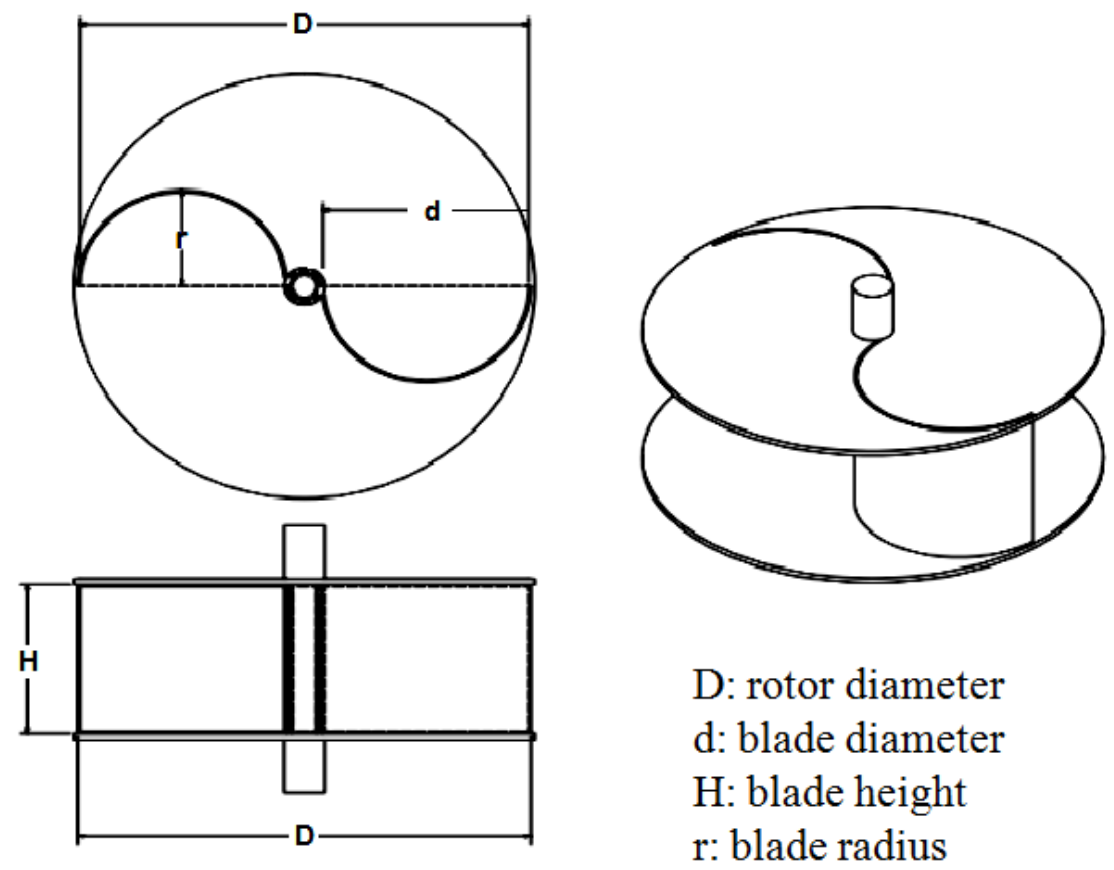

Figure 1: Schematic Diagram of the Savonius Turbine

Tip speed ratio $\left(T_{s r}\right)$ is the ratio between the tangential speed of the tip of a blade and the actual wind velocity. The tangential speed of the blade tip has capricious nominal values in accordance with the wind speed. $T_{s r}$ can be calculated using the following equation;

$$
T_{s r}=\frac{\pi D n}{60 V}
$$

where $D$ is the rotor diameter, and $n$ represents the rotor rotation. The swept area of the Savonius wind turbine can be calculated from the dimensions of the rotor.

The aspect ratio $(\alpha)$ is the ratio of the height to the turbine rotor diameter [8].

$$
\begin{aligned}
& A_{s}=D H \\
& \alpha=H / D
\end{aligned}
$$

Power coefficient is a parameter to determine the performance of the wind turbine. Generally, power coefficients for modern horizontal-axis turbines have values ranging from 0.4 to 0.5 , which are close to 70-80\% of the Betz limits [9].

Each type of turbine rotors has a different power coefficient. The following graph shows the variations of $T s r$ and rotor power coefficient values for a wide range of wind turbines. 


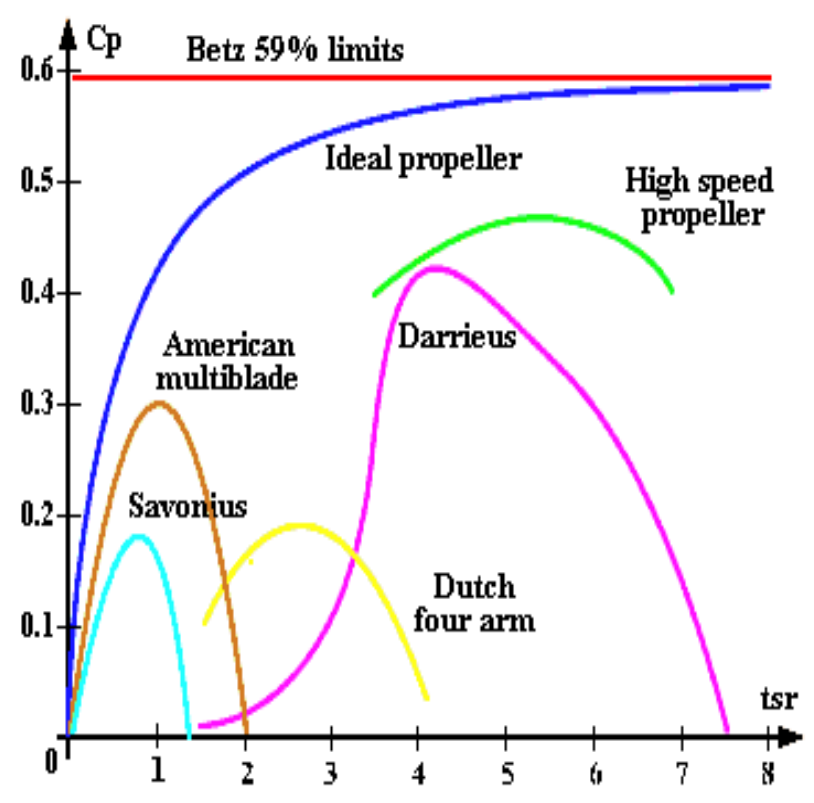

Figure 2: Diagram of $C p$-Tsr for Several Types of the Turbine [10]

\section{EXPERIMENTAL SET UP}

The schematic diagram of the experimental set up is shown in Figure 3. It consists of Savonius rotor blades, a concentrator, a vertical shaft, bearings, and a generator (model PMG 165-0.05KW/300RPM).

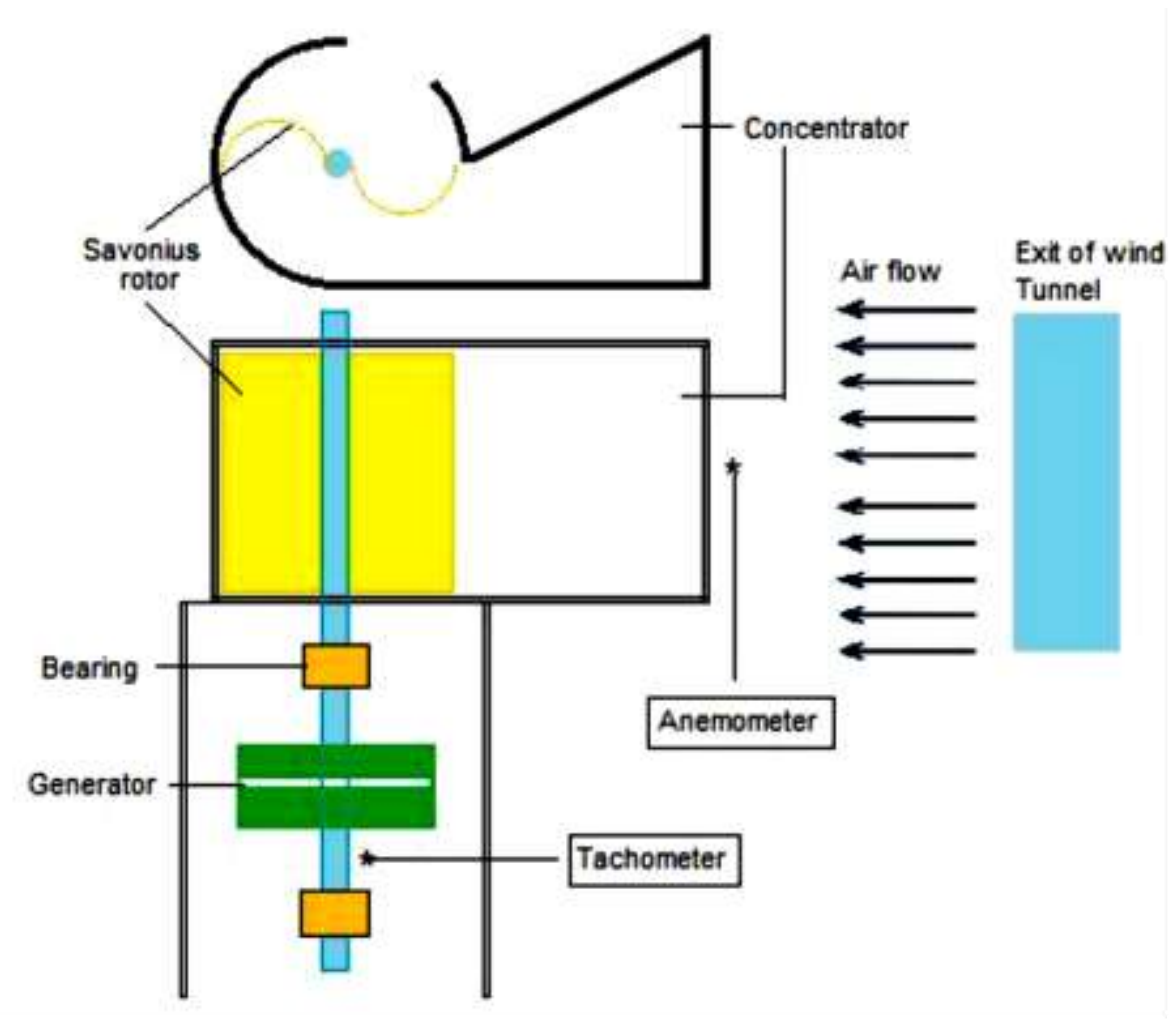

Figure 3: The schematic diagram of the experimental set up 
The tests were carried out using an open wind tunnel and performed at low wind speeds ranging from $2 \mathrm{~m} / \mathrm{s}$ to $5 \mathrm{~m} / \mathrm{s}$. The wind speed was measured using a digital anemometer HT-81, while the rotating speed of the rotor was measured using a digital laser tachometer DT-2234C $\mathrm{C}^{+}$. Current and voltage outputs of the generator were measured using a digital multitester DT-9205A.

The Savonius wind turbine was tested with a wind concentrator. The wind concentrator ratios were 1:1 (without concentrator), 2:1(C11), 3:1(C21) and 6:1(C31), see Figure 4. The ratio of the wind concentrator is defined as the comparison of input air area and the output air area of the wind concentrator $(a / b)$, see Figure $4(\mathrm{~d})$. The variations of the Savonius blade diameter employed are $6 \mathrm{~cm}, 12 \mathrm{~cm}$ and $18 \mathrm{~cm}$, see Figure 5. Furthermore, in this study, the effect of blade number is also assessed to determine its influences on the turbine performance. The numbers of the blade used were 2, 3 and 4, see Figure 6. However, the blade variations were only applied for the Savonius rotor with a diameter of $18 \mathrm{~cm}$.

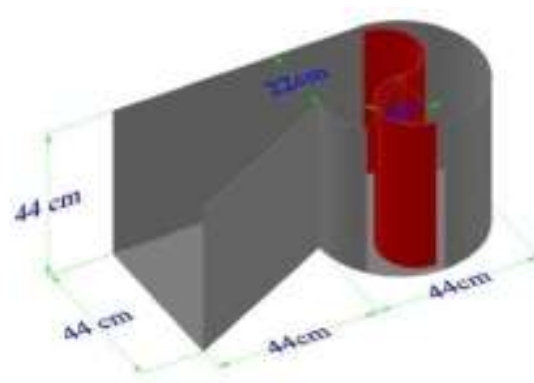

(a)

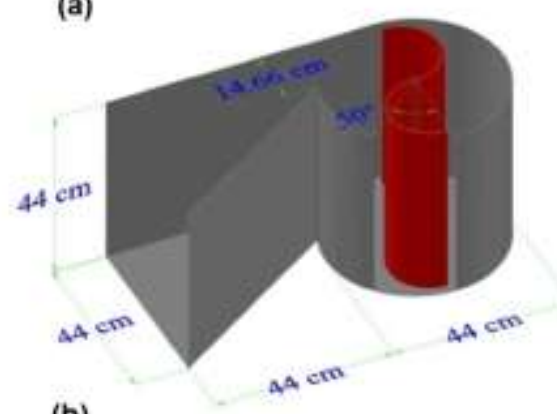

(b)

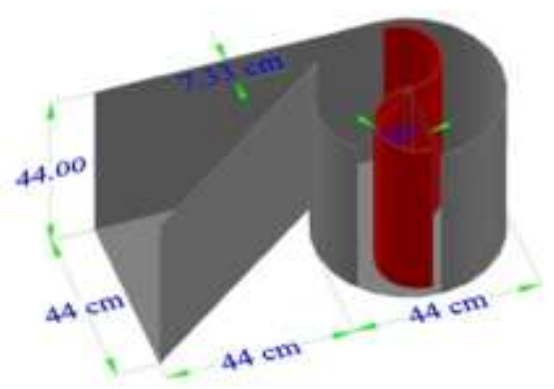

(c)

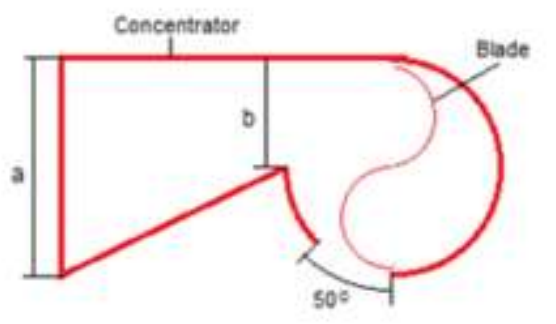

(d)

Figure 4: Wind Concentrator Design; (a) C11, (b) C21, (c) C31, (d) concentrator ratio (a/b)

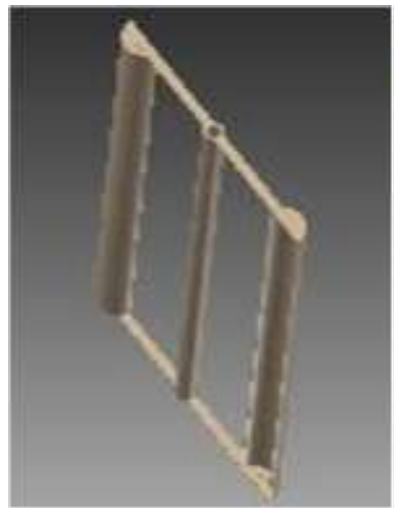

(a)

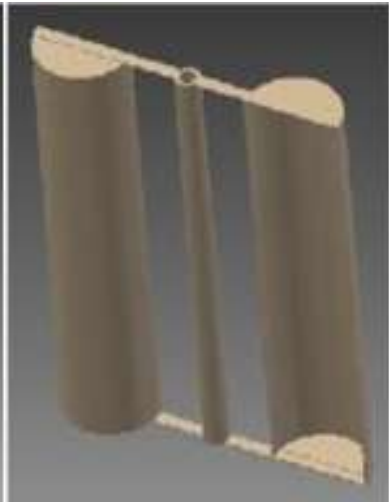

(b)

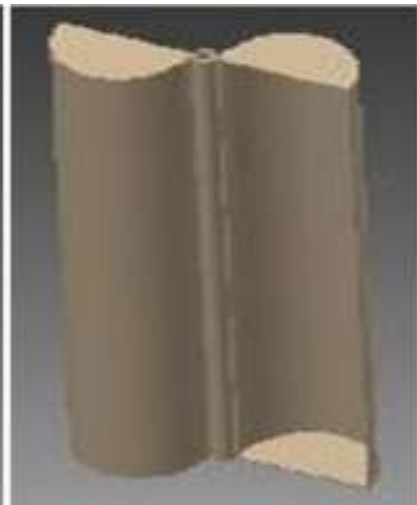

(c)

Figure 5: Variation of Blade Diameter; (a) $6 \mathrm{~cm}$, (b) $12 \mathrm{~cm}$, and (c) $18 \mathrm{~cm}$ 


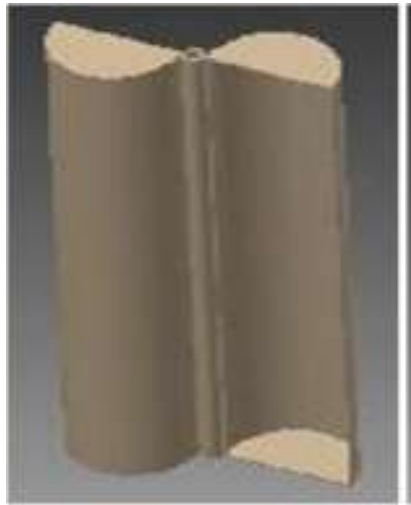

(a)

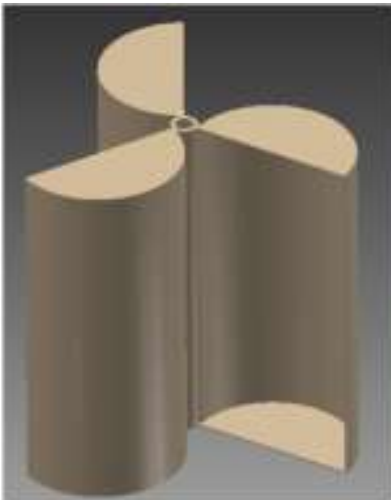

(b)

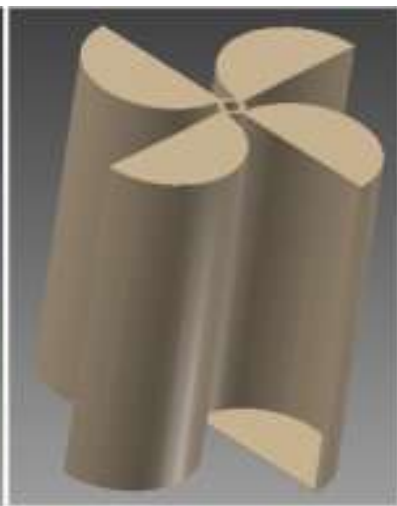

(c)

Figure 6: Variation of the Blade Number for the Rotor Diameter of $18 \mathrm{~cm}$; (a) 2 Blades, (b) 3 Blades, and (c) 4 Blades

Several cases were tested against the wind velocities to obtain the rotational rotor speed, and output voltage and current of the generator. All cases are coded and described in Table 1.

Table 1 Code of Tested Cases.

\begin{tabular}{lcccc}
\hline Code & $\begin{array}{l}\text { Concentrator } \\
\text { usage }\end{array}$ & \multicolumn{1}{l}{$\begin{array}{l}\text { Concentrator } \\
\text { ratio }\end{array}$} & $\begin{array}{l}\text { Blade } \\
\text { diameter }(\mathrm{cm})\end{array}$ & Blade number \\
\hline C0d18S2 & No & $1: 1$ & 18 & 2 \\
C11d18S2 & Yes & $2: 1$ & 18 & 2 \\
C21d18S2 & Yes & $3: 1$ & 18 & 2 \\
C31d18S2 & Yes & $6: 1$ & 18 & 2 \\
C31d18S3 & Yes & $6: 1$ & 18 & 3 \\
C31d18S4 & Yes & $6: 1$ & 18 & 4 \\
C31d12S2 & Yes & $6: 1$ & 12 & 2 \\
C31d6S2 & Yes & $6: 1$ & 6 & 2 \\
\hline
\end{tabular}

\section{RISULTS AND DISCUSSION}

The results of the experiments are presented in the form of graphs. In the preliminary experiments, three cases were tested under the same conditions at the wind velocities ranging from $2 \mathrm{~m} / \mathrm{s}$ to $5 \mathrm{~m} / \mathrm{s}$. The wind speed, rotor rotation, and power were observed and measured. The experimental $C_{p}$ and $T_{s r}$ are shown in Figure 7. $C_{p}$ is calculated using equation (1), while $P$ is also equal to $V I, V$ is the voltage and $I$ is the current, $V$ and $I$ were directly measured in the experiments using the digital multimeter. The experimental power coefficient, $C p$, increases with the tip speed ratio. This trend is found for all cases; however, as shown in Figure 7 , the $C_{p}$ values are touching each other. Some data points show that using concentrator even decreases the $C_{p}$ when $T_{s r}$ is less than 0.6 , while at $T_{s r}$ of more than 0.6 , increasing the concentrator ratio increases the power coefficient. Therefore, the effect of the concentrator ratio on the power coefficient needs to be explored further or it is advised that working with a concentrator to run a Savonius wind turbine should use $T_{s r}$ of higher than 0.6.

Meanwhile, the rotor speed increases due to the wind concentrator. The possible reason for that is because the wind concentrator acts as a device that eliminates the negative force on the turbine rotor. Furthermore, the wind concentrator also increases the wind velocity to hit the blade. As a result, the wind force pushes the blade stronger than without the wind concentrator [11]. The higher $C p$ results in better wind turbine performances. In this study, the best performance of the Savonius wind turbine is obtained with the wind concentrator ratio of 6:1. 


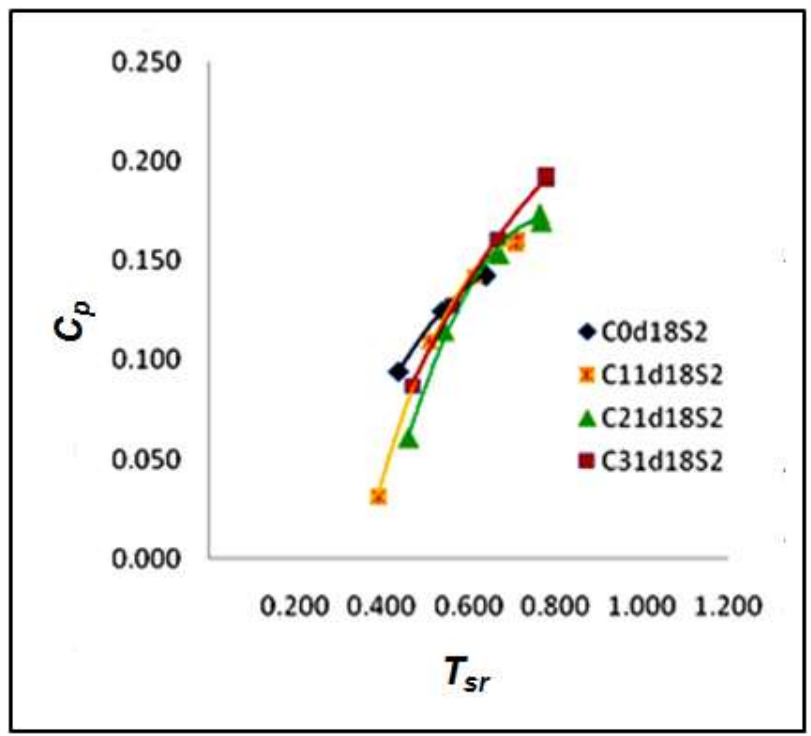

Figure 7: $C p$ versus $T_{S R}$ for Various Concentrator Ratios

Figure 8 shows the effect of wind concentrator on the rotor speed. The rotor speed depends on the wind velocity. As the wind velocity increases, the rotor rotation elevates. One interesting thing in Figure 8 is the effect of the blade number on the rotor speed. Increasing the number of the blade even decreases the rotor speed. The turbine with two blades results in higher rotor speed than that of more than 2 blades.

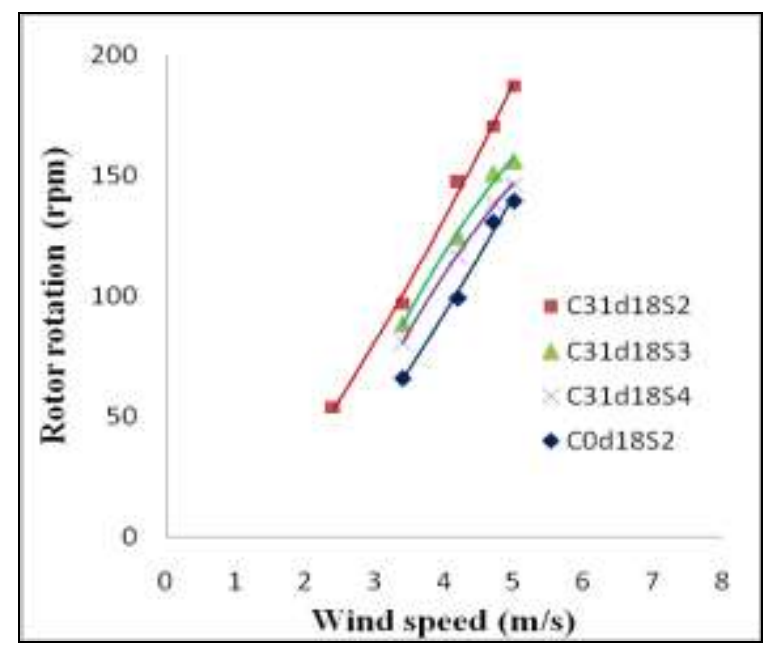

Figure 8: Effect of the Blade Number on the Rotor Rotation

Similar to the rotor speed, the power also increases with the increase in the wind velocity, see Figure 9. As the number of the blade is increased, the power of the turbine even declines. In Figure 8, although the rotor rotation decreases with the blade number, but the rotor rotation is still higher than that of the wind turbine without a concentrator. Meanwhile, in Figure 9 , the turbine with 3 and 4 blades results in the lower power than that of the turbine without a wind concentrator. Then this is not suggested to use blades of more than 2 when the turbine is equipped with a wind concentrator.

Figure 10 shows the decreased $C_{p}$ with the blade number. The $C_{p}$ of the 3 and 4 blades is lower than that of 2 blades. However, all $C_{p}$ increase with $T_{s r}$. The existing wind concentrator, just for the 2 blades, improves the rotor speed, turbine power, and power coefficient. 


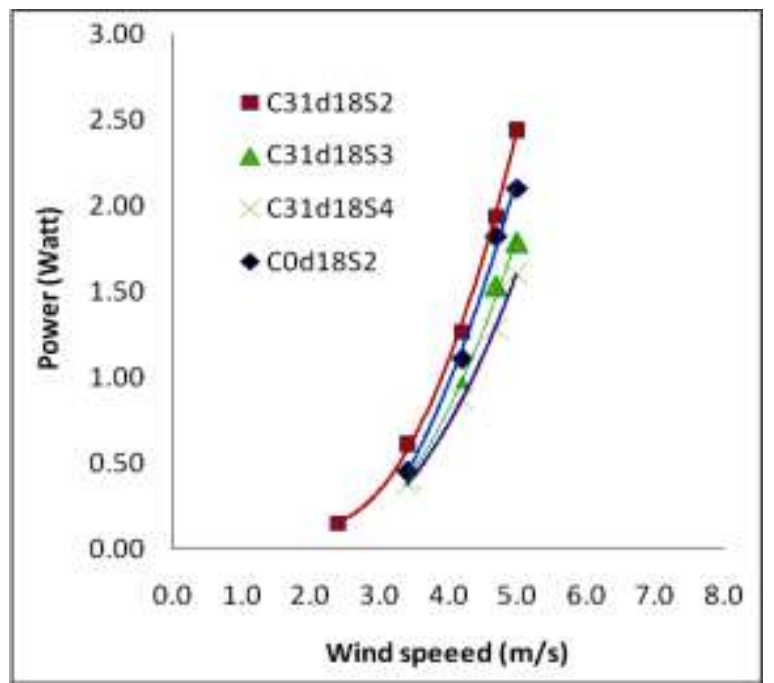

Figure 9: Effect of the Blade Number on the Turbine Power

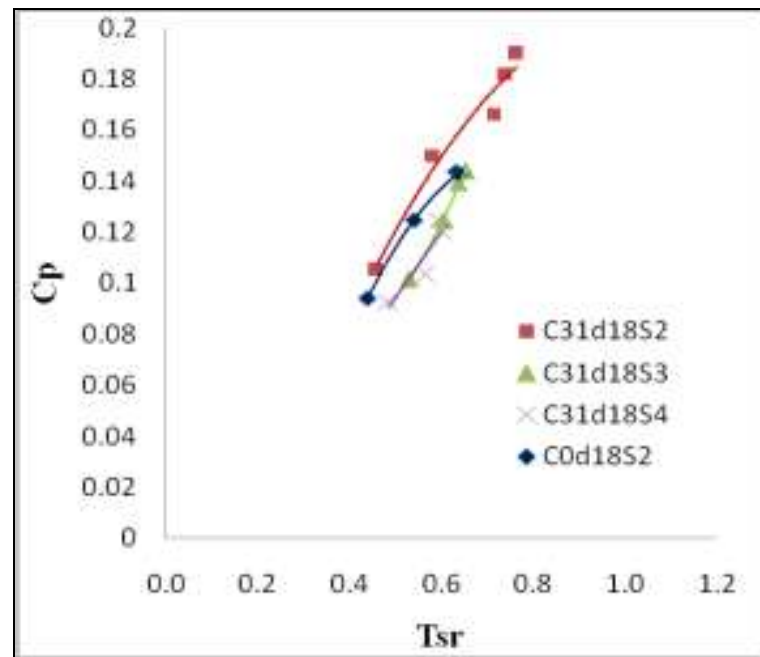

Figure 10: Effect of the Blade Number on the Power Coefficient

The second part of the study is to determine the effect of the blade diameter on the turbine performance. Figure 11 shows the effect of the blade diameter on the rotor speed. All rotors in Figure 11 were equipped with a wind concentrator having an aspect ratio of 6:1. The effect of the blade diameter on the rotor speed is not clear. Rotor blades with a diameter of $6 \mathrm{~cm}$ result in a higher rotor speed than the rotor blades with a diameter of $12 \mathrm{~cm}$, but lower than the rotor blades with a diameter of $18 \mathrm{~cm}$. Hence, this needs a further comprehensive research.

Figure 12 presents the effect of the blade diameter on the turbine power. Similar to the rotor speed, the effect of the blade diameter does not show a clear effect. The biggest blade diameter results in the lowest power; while the smallest blade diameter gives the power that locates between the power of the $12 \mathrm{~cm}$ blade diameter and $18 \mathrm{~cm}$ blade diameter. Nevertheless, from Figures 11 to 13, the rotor with a blade diameter of $12 \mathrm{~cm}$ gives the best performance. Therefore, it is recommended to be implemented with a wind concentrator ratio of 6: 1 . 


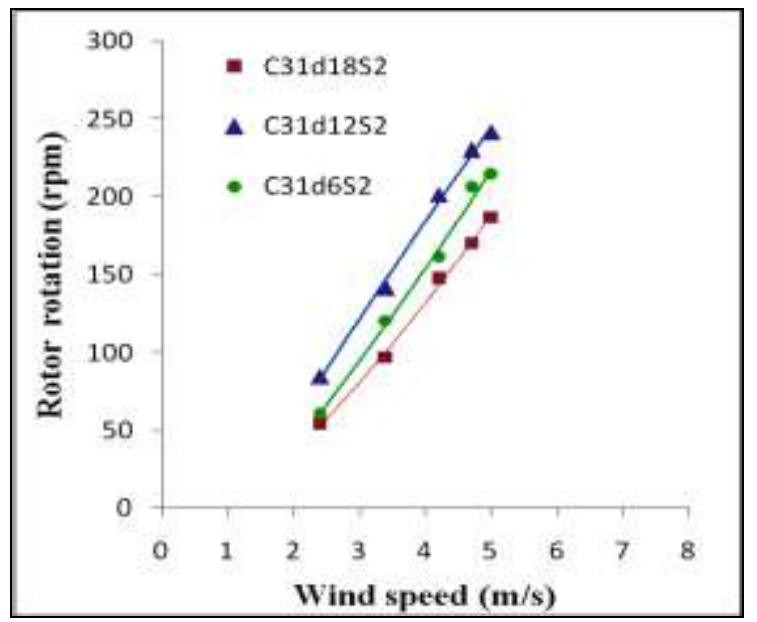

Figure 11: Effect of the Blade Diameter on the Rotor Rotation

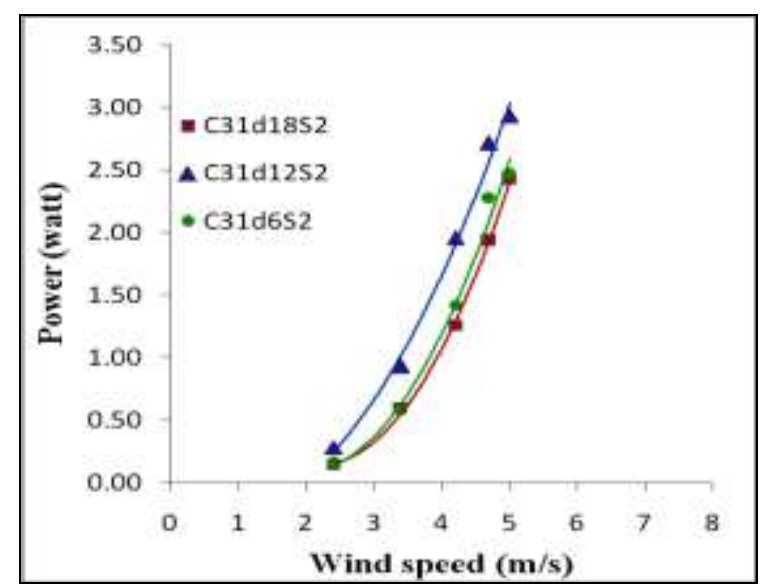

Figure 12: Effect of the Blade Diameter on the Turbine Power

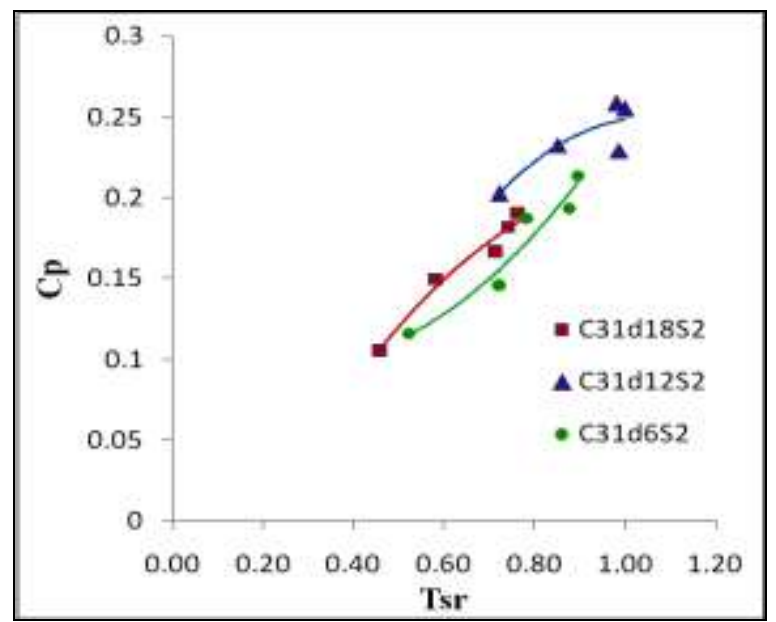

Figure 13: Effect of the Blade Diameter on the Power Coefficient

\section{CONCLUSION}

The concentrator serves to increase the wind velocity; consequently, the addition of the concentrator elevates the speed of rotor rotation, the turbine power, and the power coefficient. The wind turbine with two blades produces a stable rotation, thus it provides the best performance compared to the three and four blades. The use of $12 \mathrm{~cm}$ blade diameter is the most suitable wind turbine with a concentrator ratio of $6: 1$. 


\section{ACKNOWLEDGEMENT}

This research is funded by the competitive research grant provided by the Ministry of Research, Technology and Higher Education with the contract number No.62Z/SPP-HB/UN18.12/PL/2016.

\section{REFERENCES}

[1] I.I. Paraschivoiu, Wind turbine design, Presses Internatinales Polytechnique, Canada, 2002.

[2] J.V. Akwa, H.A. Vielmo and A.P. Petry, A review on the performance of savonius wind turbines, Renewable and Sustainable Energy Review, Vol. 16, No. 5, pp. 3054-3064, 2012.

[3] H.A. Ali, Experimental comparison study for Savonius wind turbine of two \& three blades at low wind speed, Int.J. Modern Research IJMER, Vol. 3, No. 5, pp. 2978-2986, 2013.

[4] A. Vaishali, S.A. Patil and A.A. Thakur, Optimization of Savonius rotor for wind turbine, Int. J. Advances in Engineering and Technology, Vol. 7, No. 4, pp. 1294-1299, 2014.

[5] Z. Driss, A. Damak and M.S. Abid, Evaluation of the Savonius wind rotor performance for different external overlap ratio, Int. J. Fluids Mechanics \& Thermal Sciences, Vol. 1, No. 1, pp. 14-19, 2015.

[6] L.F. Rus, Experimental study on the increase of the efficiency of vertical wind turbines by equipping them with wind concentrators, J. Sustainable Energy, Vol. 3, No. 1, pp. 30-35, 2012.

[7] S.C. Balineni, S.R. Krisnha, B.S. Kumar and G.V. Kumar, Design and fabrication of Savonius vertical axis wind turbin, Department of Mechanical Engineering Gokaraju Rangaraju Institute of Engineering and Technology, Jawaharlal Nehru Technological University, 2011.

[8] C.R. Patel, V.K. Patel, S.V. Prabhu and T.I. Eldho, Investigation of overlap ratio for Savonius type vertical axis hydro turbine, Int. J. Soft Computing and Engineering (IJSCE), Vol. 3, No. 2, pp. 379-383, 2013.

[9] E. Hau, Wind Turbines, Springer, New York, 2006.

[10] M. D'Ambrosio and M. Medaglia, Vertical axis wind turbines, History, Technology and Applications, Högskolan Halmstad, 2010.

[11]B.D. Altan and M.A. Atilgan, A study on increasing the performance of Savonius wind rotors, Int. J. Mechanical Science and Technology, Vol. 26, No. 5, pp. 1493-1499, 2012.

[12] N.H. Mahmoud, A.A. Haroun, E. Wahba and M.H. Nasef, An experimental study on improvement of Savonius rotor performance, Alexandria Engineering Journal, Vol. 51, pp. 19-25, 2012. 